\title{
Perfil clínico de crianças internadas com vírus sincicial respiratório (VSR): análise em uma cidade do interior paulista de 2016 a 2017
}

\author{
Clinical profile of hospitalized children with respiratory syncytial virus (RSV): analysis in a \\ city in the interior of São Paulo from 2016 to 2017 \\ Perfil clínico de niños hospitalizados com vírus respiratório sincitial (VSR): análisis em \\ uma ciudad del interior de São Paulo de 2016 a 2017
}

Franciele Rodrigues de Oliveira ${ }^{1 *}$, Raquel de Souza ${ }^{1}$, Roberto Salvador Martins ${ }^{1}$, Maraísa Centeville ${ }^{1}$, Christiane Ambrosio do Nascimento ${ }^{1}$, Fernanda de Souza do Martins ${ }^{1}$.

\section{RESUMO}

Objetivo: Identificar e comparar o perfil epidemiológico e clínico de crianças com desconforto respiratório que realizaram teste rápido para VSR e/ou swab para o vírus H1N1 entre 2016 e 2017. Métodos: Os dados foram coletados do livro de controle dos testes para VSR e prontuários em um hospital no interior de São Paulo. Foram incluídas crianças menores de dois anos, com desconforto respiratório, que realizaram o teste para VSR e/ou swab para o vírus H1N1, de abril a junho de 2016 e 2017. Para análise estatística foram utilizados os testes Exato de Fisher e Mann-Whitney (significativo $P=<0,05$ ). Resultados: Em 2016, 84 crianças foram incluídas, com idade média de 6.1 meses, $42.9 \%$ apresentaram VSR positivo. Destas, $33.3 \%(P=0.0010)$ internaram na UTI, com tendência de maior uso $(P=0.0933)$ e tempo em ventilação mecânica $(P=0.0456)$. Em 2017, foram incluídas 165 crianças, com média de idade de 6.4 meses, 49.1\% apresentaram VSR positivo. Destas, $86.1 \%(P=0.002)$ foram diagnosticadas com bronquiolite, $24.7 \%(P=0.031)$ utilizaram inalação hipertônica e 56.8\% ( $P=0.016)$ oxitenda. Conclusão: A incidência do VSR foi maior em 2017, embora, em 2016, os pacientes com VSR positivo tenham internado com maior frequência em UTI, apresentando tempo mais prolongado e uso mais frequente da ventilação mecânica.

Palavras chaves: Vírus sincicial respiratório humano, Influenza humana, Criança, Insuficiência respiratória.

\begin{abstract}
Objective: To identify and compare the epidemiological and clinical profile of children with respiratory distress who underwent rapid testing for RSV and / or swab for the H1N1 virus between 2016 and 2017. Methods: Data were collected from the RSV test control book and medical records at a hospital in the interior of São Paulo. Children under two years old with respiratory distress were included, who were tested for RSV and / or swab for the H1N1 virus, from April to June 2016 and 2017. For statistical analysis, Fisher's exact and MannWhitney tests were used. (significant $P=<0.05$ ). Results: In 2016, 84 children were included, with a mean age of 6.1 months, $42.9 \%$ had a positive RSV. Of these, 33.3\% $(P=0.0010)$ were admitted to the ICU, with a tendency to greater use $(P=0.0933)$ and time on mechanical ventilation $(P=0.0456)$. In 2017,165 children were included, with an average age of 6.4 months, $49.1 \%$ had a positive RSV. Of these, $86.1 \%(P=0.002)$ were diagnosed with bronchiolitis, $24.7 \%(P=0.031)$ used hypertonic inhalation and $56.8 \%(P=0.016)$ were treated with bronchiolitis. Conclusion: The incidence of RSV was higher in 2017, although in 2016, patients with positive RSV were hospitalized more frequently in the ICU, with longer duration and more frequent use of mechanical ventilation.
\end{abstract}

Keywords: Human respiratory syncytial virus, Human influenza, Child, Respiratory insufficiency.

\section{RESUMEN}

Objetivo: Identificar y comparar el perfil epidemiológico y clínico de los niños con molestias respiratorias que se sometieron a pruebas rápidas de VSR y/o pruebas del virus H1N1 entre 2016 y 2017. Métodos: Los datos fueron recolectados del libro de control de la prueba del VSR y de las historias clínicas de un hospital del interior de São Paulo. Se incluyeron los niños menores de dos años, con dificultad respiratoria, que realizaron

\footnotetext{
${ }^{1}$ Hospital Municipal Dr. Mário Gatti (HMMG), Campinas - SP. *E-mail: enf.franciele2018@gmail.com
} 
examen de VSR y/o para el virus H1N1 de abril a junio de 2016 y 2017. Para el análisis estadístico, se utilizaron las pruebas Exactas de Fisher y Mann-Whitney (significativo $P=<0,05$ ). Resultados: En 2016, se incluyeron 84 niños, con una edad media de 6,1 meses, el 42,9\% tenía una VSR positiva. De ellos, el 33,3\% $(\mathrm{P}=0,0010)$ fueron admitidos en la $\mathrm{UCl}$, con una tendencia de mayor uso $(\mathrm{P}=0,0933)$ y tiempo en ventilación mecánica $(P=0,0456)$. En 2017, se incluyeron 165 niños, con una edad media de 6,4 meses, el 49,1\% tenía el VSR positivo. De ellos, el 86,1\% ( $P=0,002)$ fueron diagnosticados con bronquiolitis, el $24,7 \%(P=0,031)$ usaron inhalación hipertónica y el $56,8 \%(P=0,016)$ oxitenda. Conclusión: La incidencia de VSR fue mayor en 2017, aunque en 2016, los pacientes con VSR positiva fueron ingresados con mayor frecuencia en la UCl, presentando un uso más prolongado y frecuente de la ventilación mecánica.

Palabras clave: Virus sincitial respiratorio humano, Gripe humana, Niños, Insuficiencia respiratoria.

\section{INTRODUÇÃO}

As infecções respiratórias agudas são capazes de acometer as vias aéreas superiores, divididas em nariz, fossas nasais, seios perinasais, boca, faringe, laringe, estendendo-se ao ouvido médio, assim como as vias aéreas inferiores, sendo elas: traqueia, brônquios, bronquíolos e pulmões (FRAUCHES DO, et. al., 2017).

As infecções respiratórias que acometem as vias aéreas inferiores em geral apresentam maior gravidade e especialmente nos primeiros anos de vida, representam as principais causas pela procura por serviços de atendimento de emergência e hospitalizações. Tais infecções implicam em grandes impactos na qualidade de vida em curto e longo prazo em crianças e familiares, bem como resultam em elevados custos para 0 sistema único de saúde (SUS) (FRAUCHES DO, et. al., 2017; SOUZA APD, et. al., 2016).

Essas infecções podem ser classificadas de acordo com o agente etiológico, podendo ser de origem viral, bacteriana e fúngica. Entretanto, a maior incidência é de etiologia viral, de forma que o vírus possa ser o principal patógeno ou predispor as infecções bacterianas secundárias. Alguns dos vírus mais prevalentes na infância são o vírus sincicial respiratório (VSR), influenza $A$ e B, parainfluenza, metapneumovírus humano e adenovírus (BENITES ECA, et. al., 2014; DE PAULIS M, et. al., 2011).

Em menores de cinco anos, essas infecções são as causas mais frequentes de febre, e no geral, é representada, especialmente pela pneumonia adquirida na comunidade e pela bronquiolite viral aguda. Além disso, em lactentes a bronquiolite viral aguda causada pelo VSR é o principal motivo para as internações hospitalares e o vírus influenza é um dos agentes etiológicos mais comuns nos casos de pneumonia viral (SOUZA APD, et. al., 2016; SOUZA PG, et. al., 2018; ALVAREZ AE, et. al., 2013; FONSECA S, et. al., 2017).

$O$ vírus sincicial respiratório é conhecido mundialmente como um importante agente infeccioso do trato respiratório em crianças. A organização mundial da saúde estima que o vírus infecte 64 milhões de indivíduos e cause 160.000 óbitos por ano em todo o mundo (MESQUITA FS, et. al., 2017).

$O$ vírus possui dois subgrupos denominados, $A$ e $B$, apresenta sazonalidade no outono e inverno com oscilações regionais importantes, sendo que no Brasil, na região sudeste as infecções pelo VSR iniciam-se em abril e apresentam maior número de casos em maio e junho (MONTEIRO AIMP, et. al., 2014).

As infecções que acometem o trato respiratório inferior são responsáveis por altas taxas de adoecimento, sendo majoritariamente de etiologia viral, e representam importante causa de morbimortalidade, principalmente em crianças menores de dois anos de idade (MAGALHAES EF, et al., 2017; FERLINI R, et al., 2016).

Entre os agentes virais mais prevalentes, destacam-se o vírus sincicial respiratório (VSR) e o vírus influenza A de origem suína, o H1N1 (as letras correspondem a duas proteínas da superfície do vírus, sendo $\mathrm{H}$ a proteína hemaglutinina e a letra $\mathrm{N}$ à proteína neuraminidade e o número $1 \mathrm{a}$ ordem que que elas foram registradas). Ambos circulam 0 ano todo, todavia, apresentam comportamento sazonal, aumentando 0 número de casos principalmente no outono e inverno (ALVAREZ AE, et al., 2013).

As infecções respiratórias causadas por esses vírus variam amplamente, desde as formas leves, como resfriados comuns, até as formas graves, com necessidade de internação em unidade de terapia intensiva e uso de ventilação mecânica (ALVAREZ AE, et al., 2013; MONTEIRO AIMP, et al., 2014; MOURA AA, et al., 2017). 
Pesquisas epidemiológicas e clínicas sobre o acometimento de infecções respiratórias provocadas por esses vírus em crianças permitem traçar políticas públicas eficazes no combate destes agravos, em âmbito local e nacional. Dessa forma, justifica-se o conhecimento do impacto das infecções por esses vírus nas crianças atendidas em nosso serviço (ALVAREZ AE, et al., 2013; MONTEIRO AIMP, et al., 2014; MOURA AA, et al., 2017).

Portanto, a pesquisa objetivou identificar e comparar o perfil epidemiológico e clínico de crianças com desconforto respiratório que realizaram teste rápido para VSR e/ou swab para o vírus H1N1 entre 2016 e 2017.

\section{MÉTODOS}

Trata-se de um estudo quantitativo e retrospectivo que inclui uma amostra composta por crianças de zero a dois anos atendidas no pronto socorro infantil de um hospital no interior paulista com desconforto respiratório e que realizaram o teste para o VSR, e destes os que coletaram swab de investigação para o vírus Influenza A, subtipo H1N1. O projeto foi aprovado pela comissão de ética em pesquisa da instituição (parecer ํo 3.140.539).

O hospital é reconhecido como de ensino e referência em traumatologia e integra o projeto Hospital Sentinela em Síndrome Gripal (SG) e Síndrome Respiratória Aguda Grave (SRAG). Entre as unidades assistenciais direcionadas para o atendimento pediátrico, está o pronto socorro infantil (PSI), enfermaria pediátrica e unidade de terapia intensiva pediátrica (UTIP), que possuem equipes multiprofissionais, que atuam exclusivamente no atendimento às crianças.

Foram selecionadas para o estudo crianças de zero a dois anos que apresentaram desconforto respiratório à admissão e que realizaram o teste rápido para VSR, com resultado registrado no livro de controle de crianças submetidas ao teste, localizado no PSI durante o período de abril a junho do ano de 2016 e 2017. Foram considerados com desconforto respiratório aquelas que apresentavam no mínimo um sinal clínico de uso da musculatura acessória (batimento de aleta nasal, retração de fúrcula, subcostal e intercostal) e/ou queda da saturação > 94\% em ar ambiente.

Destes pacientes, que houve coleta do teste para VSR, alguns tiveram a indicação médica da coleta de swab para investigação do vírus influenza A, subtipo $\mathrm{H} 1 \mathrm{~N} 1$. Os critérios usados para a indicação da coleta do swab e os sinais e sintomas de síndrome respiratória aguda grave, em que tem-se tosse, febre, dor de garganta, e algum sinal de insuficiência respiratória, como batimento de aleta nasal, uso de musculatura respiratória acessória, aumento da frequência respiratória.

Segundo a rotina de atendimento do hospital, a detecção da infecção pelo VSR é feita através do aspirado de secreção da nasofaringe, realizada por teste imunocromatográfico in vitro, o qual detecta o antígeno de proteína de fusão do vírus, o chamado teste rápido.

A identificação do vírus H1N1 é obtida através de amostras de exsudado da nasofaringe e orofaringe ou lavado bronco-alveolar, que são submetidos à técnica de reação em cadeia da polimerase (PCR) e analisados pelo laboratório do Instituto Adolpho Lutz. Quando a criança se encontrava em ventilação mecânica, coletavase o secretado traqueal, através de aspiração e quando a criança estava em respiração espontânea, coletavase swab, através de três hastes flexíveis (uma em cada narina e uma orofaríngea).

As coletas para ambos os testes foram realizadas apenas uma vez, para fins epidemiológicos e diagnósticos. $\mathrm{Na}$ instituição ainda não existe rotina de repetição dos exames, como por vezes está preconizado em outros serviços.

Foram excluídas as crianças com idade superior a dois anos e/ou que não realizaram o teste para detecção do VSR ou que realizaram o teste, mas o resultado não constava no livro de controle de testes para VSR, no período de abril a junho de 2016 e 2017.

As crianças incluídas na pesquisa foram agrupadas conforme o resultado dos testes para VSR. Destas, foram analisadas também aquelas que coletaram swab para investigação do vírus influenza A, subtipo H1N1, 
estando os resultados disponíveis no núcleo de epidemiologia hospitalar (NEH). De acordo com os resultados, foram formados dois grupos para a análise estatística, sendo o primeiro grupo de paciente com VSR positivo versus com VSR negativo e o segundo grupo de pacientes com H1N1 positivo versus com H1N1 negativo.

A pesquisa de dados clínicos e epidemiológicos das crianças incluídas no estudo foi realizada através dos prontuários, disponíveis no serviço de arquivo médico (SAME). Para a análise e comparação das variáveis entre os grupos foram coletados dos prontuários os seguintes dados: (1) sexo; (2) idade; (3) prematuridade; (4) mês de coleta do VSR; (5) internação em unidade de terapia intensiva (UTIP); (6) tempo de internação no pronto socorro infantil (PSI), UTIP e enfermaria de pediatria; (7) uso de corticoides; (8) antibioticoterapia; (9) uso de oseltamivir; (10) uso de inalação salina hipertônica; (11) oxigenoterapia (cateter tipo óculos, oxitenda, máscara de Venturi, ventilação não-invasiva e ventilação mecânica); (12) tempo em ventilação mecânica; (13) diagnóstico médico e (14) mortalidade hospitalar. De acordo com o Ministério da Saúde, considera-se prematuridade idade gestacional menor que 37 semanas (BRASIL, 2013).

No livro de registros dos testes para VSR havia 119 crianças registradas no período de abril a junho de 2016. Destas, foram excluídas 35. Destas, três crianças não tinham o resultado do teste rápido para VSR registrado no livro e 32 tinham mais que dois anos de idade. Assim, a amostra foi de 84 crianças. Destas, em 12 foram coletados swabs para investigação do vírus H1N1 (Figura 1).

Em 2017, das 234 crianças registradas no livro, 69 foram excluídas. Destas, cinco foram excluídas devido ao não registro do resultado do teste de VSR no livro, e 64 tinham idade superior a dois anos. Em 2017, a amostra foi de 165 crianças. Destas, 53 crianças tiveram o swab de investigação para o vírus H1N1 coletado (Figura 2).

Figura 1 - Fluxograma de inclusão e exclusão de pacientes no estudo em 2016.

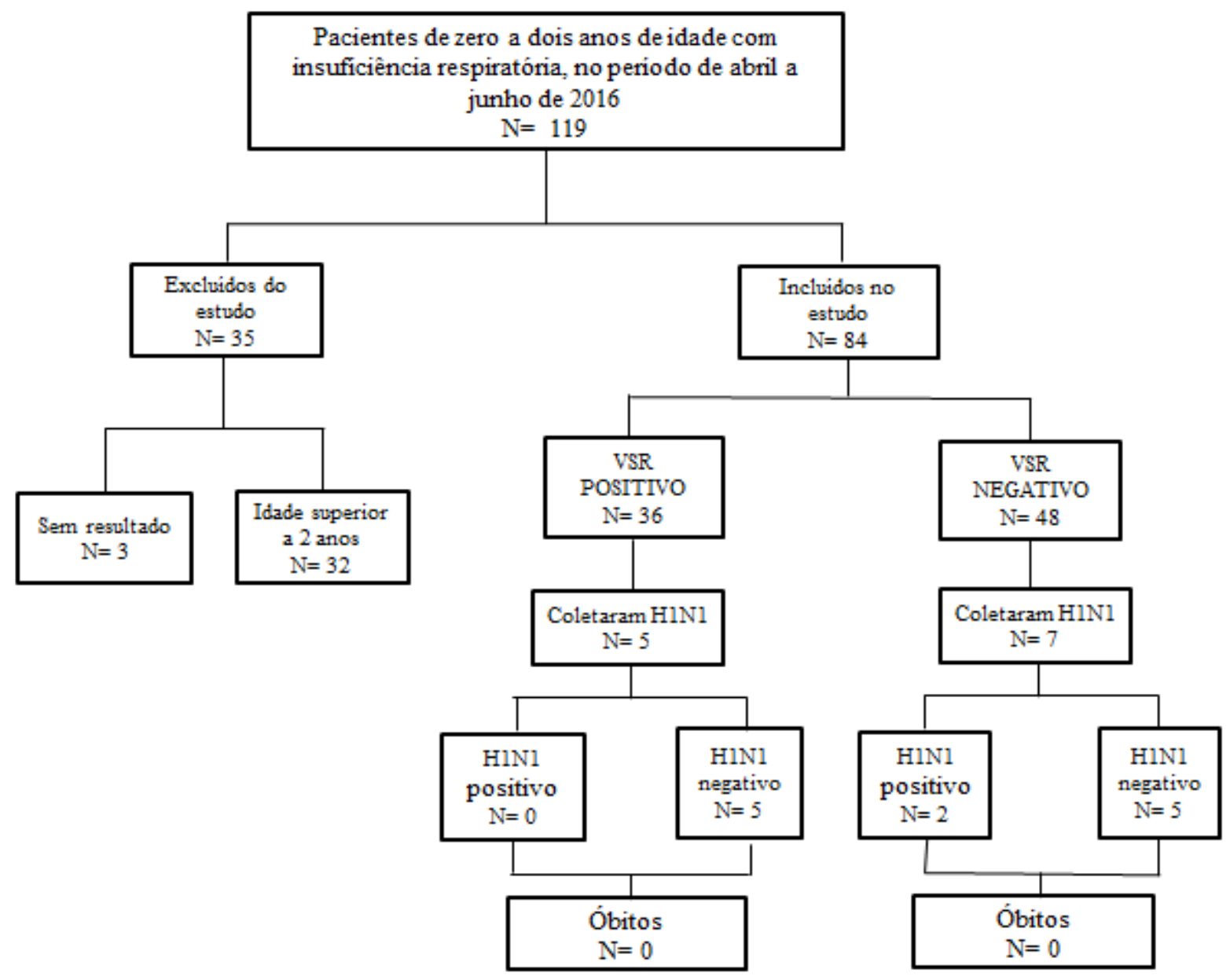

Fonte: Oliveira RF, et al., 2020. 
Figura 2 - Fluxograma de inclusão e exclusão de pacientes no estudo em 2017.

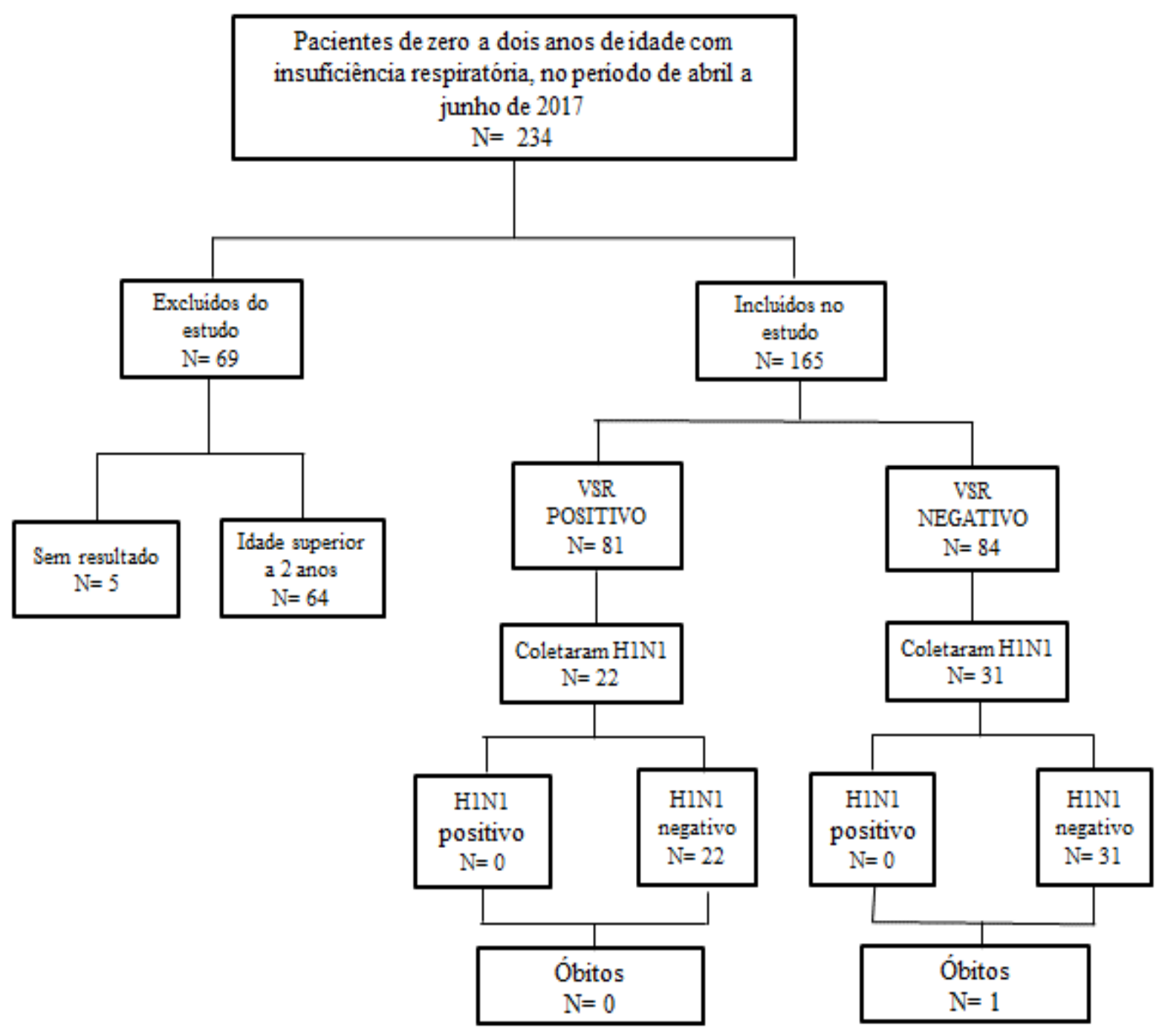

Fonte: Oliveira RF, et al., 2020.

\section{RESULTADOS}

A Tabela 1 evidencia que comparando as características entre os grupos de crianças com VSR positivo e VSR negativo, houve predomínio do sexo masculino e o diagnóstico de bronquiolite foi o mais frequente, embora sem diferença significativa. $O$ uso de oseltamivir apresentou diferença significativa, sendo menos indicado em pacientes com VSR positivo. A taxa de internação em UTI foi significativamente maior em crianças não infectadas pelo VSR. Entretanto, a média de dias de permanência na UTI foi maior nos pacientes com VSR positivo, bem como o uso mais frequente e em maior tempo de permanência de ventilação mecânica. 
Tabela 1 - Características clínicas e demográficas dos pacientes em 2016.

\begin{tabular}{|c|c|c|c|c|}
\hline Características & $\begin{array}{c}\text { VSR negativo } \\
(\mathrm{n}=48)\end{array}$ & $\begin{array}{c}\text { VSR positivo } \\
(\mathrm{n}=36)\end{array}$ & $\begin{array}{c}\text { Total } \\
(\mathrm{n}=84)\end{array}$ & Valor $\boldsymbol{P}$ \\
\hline $\begin{array}{l}\text { Idade: } 0 \text { a } 24 \text { meses } \\
\text { Média } \pm D P(n)\end{array}$ & $6.5 \pm 4.9(n=48)$ & $5.7 \pm 5.4(n=36)$ & $6.1 \pm 5.2(n=84)$ & 0.2890 \\
\hline $\begin{array}{l}\text { Sexo, } \mathbf{n}(\%) \\
\text { Feminino } \\
\text { Masculino }\end{array}$ & $\begin{array}{l}16(33.3) \\
32(66.7)\end{array}$ & $\begin{array}{l}16(44.4) \\
20(55.6)\end{array}$ & $\begin{array}{l}32(38.1) \\
52(61.9)\end{array}$ & 0.418 \\
\hline $\begin{array}{l}\text { Prematuridade, } \mathbf{n}(\%) \\
\text { Não } \\
\text { Sim }\end{array}$ & $\begin{array}{l}43(89.6) \\
05(10.4)\end{array}$ & $\begin{array}{l}28(77.8) \\
08(22.2)\end{array}$ & $\begin{array}{l}71(84.5) \\
13(15.5)\end{array}$ & 0.1388 \\
\hline $\begin{array}{l}\text { Bronquiolite, } \mathbf{n}(\%) \\
\text { Não } \\
\text { Sim }\end{array}$ & $\begin{array}{l}08(16.7) \\
40(83.3)\end{array}$ & $\begin{array}{l}05(13.9) \\
31(86.1)\end{array}$ & $\begin{array}{l}13(15.5) \\
71(84.5)\end{array}$ & 0.7276 \\
\hline $\begin{array}{l}\text { Pneumonia, n (\%) } \\
\text { Não } \\
\text { Sim }\end{array}$ & $\begin{array}{l}38(79.2) \\
10(20.8)\end{array}$ & $\begin{array}{l}27(75.0) \\
09(25.0)\end{array}$ & $\begin{array}{l}65(77.4) \\
19(22.6) \\
\end{array}$ & 0.6515 \\
\hline $\begin{array}{l}\text { Uso antibiótico, } \mathbf{n}(\%) \\
\text { Não } \\
\text { Sim }\end{array}$ & $\begin{array}{l}38(79.2) \\
10(20.8) \\
\end{array}$ & $\begin{array}{l}23(63.9) \\
13(36.1) \\
\end{array}$ & $\begin{array}{l}61(72.7) \\
23(27.3) \\
\end{array}$ & 0.191 \\
\hline $\begin{array}{l}\text { Uso oseltamivir, } \mathbf{n}(\%) \\
\text { Não } \\
\text { Sim }\end{array}$ & $\begin{array}{l}27(56.2) \\
21(43.8)\end{array}$ & $\begin{array}{l}30(83.3) \\
06(16.7)\end{array}$ & $\begin{array}{l}57(67.9) \\
27(32.1)\end{array}$ & 0.017 \\
\hline $\begin{array}{l}\text { Uso corticoide, } \mathbf{n}(\%) \\
\text { Não } \\
\text { Sim }\end{array}$ & $\begin{array}{l}23(47.9) \\
25(52.1)\end{array}$ & $\begin{array}{l}17(47.2) \\
19(52.8)\end{array}$ & $\begin{array}{l}40(47.6) \\
44(52.4)\end{array}$ & 0.9497 \\
\hline $\begin{array}{l}\text { Inalação Hipertônica, n (\%) } \\
\text { Não } \\
\text { Sim }\end{array}$ & $\begin{array}{l}34(70.8) \\
14(29.2) \\
\end{array}$ & $\begin{array}{l}27(75.0) \\
09(25.0)\end{array}$ & $\begin{array}{l}61(72.6) \\
23(27.4)\end{array}$ & 0.6717 \\
\hline $\begin{array}{l}\text { Média (dias) enfermaria } \\
\text { Média } \pm D P(n)\end{array}$ & $4.5 \pm 3.0(n=17)$ & $3.4 \pm 2.7(n=18)$ & $3.9 \pm 2.9(n=35)$ & 0.2490 \\
\hline $\begin{array}{l}\text { Internação Unidade de terapia } \\
\text { intensiva, } \mathbf{n}(\%) \\
\text { Sim } \\
\text { Não }\end{array}$ & $\begin{array}{c}45(93.8) \\
03(6.2)\end{array}$ & $\begin{array}{l}23(66.7) \\
12(33.3)\end{array}$ & $\begin{array}{l}68(82.1) \\
15(17.9)\end{array}$ & 0.0010 \\
\hline $\begin{array}{l}\text { Média (dias) Unidade terapia } \\
\text { intensiva } \\
\text { Média } D P(n)\end{array}$ & $9.0 \pm 5.3(n=3)$ & $11.5 \pm 10.7(n=12)$ & $11.0 \pm 9.8(n=15)$ & 0.7698 \\
\hline $\begin{array}{l}\text { Oxitenda, n (\%) } \\
\text { Não } \\
\text { Sim }\end{array}$ & $\begin{array}{l}12(25.0) \\
36(75.0)\end{array}$ & $\begin{array}{c}7(19.4) \\
29(80.6)\end{array}$ & $\begin{array}{l}19(22.6) \\
65(77.4)\end{array}$ & 0.5470 \\
\hline $\begin{array}{l}\text { Ventilação não invasiva, n (\%) } \\
\text { Não } \\
\text { Sim }\end{array}$ & $\begin{array}{l}43(89.6) \\
05(10.4)\end{array}$ & $\begin{array}{l}32(88.9) \\
04(11.1)\end{array}$ & $\begin{array}{l}75(89.3) \\
09(10.7)\end{array}$ & 1.0000 \\
\hline $\begin{array}{l}\text { Ventilaçao mecânica, n (\%) } \\
\text { Não } \\
\text { Sim }\end{array}$ & $\begin{array}{l}44(91.7) \\
04(8.3)\end{array}$ & $\begin{array}{l}29(80.6) \\
07(19.4)\end{array}$ & $\begin{array}{l}73(87.0) \\
11(13.0)\end{array}$ & 0.0933 \\
\hline 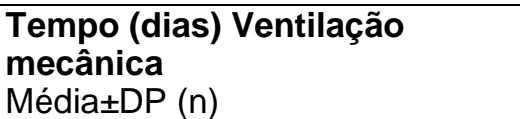 & $5.3 \pm 1.5(n=4)$ & $11.6 \pm 6.1 \quad(n=7)$ & $9.7 \pm 5.8(n=11)$ & 0.0456 \\
\hline
\end{tabular}

Fonte: Oliveira RF, et al., 2020.

Na Tabela 2, nota-se que em 2017 houve predomínio do sexo masculino entre as crianças que realizaram o teste rápido para VSR independente do resultado, e que o diagnóstico de bronquiolite foi significativamente mais frequente em pacientes com VSR positivo. Crianças com VSR negativo tenderam a ter diagnostico mais frequente de pneumonia. Com relação ao uso de oseltamivir, as crianças com VSR negativo fizeram uso significativamente mais frequente. Os pacientes infectados pelo VSR internaram com mais frequência na UTI, utilizaram mais o ventilador mecânico e permaneceram maior tempo com seu uso, apesar de não haver diferença significativa. $\mathrm{O}$ uso de oxitenda e inalação hipertônica foram significativamente mais frequentes entre crianças com VSR positivo. 
Tabela 2 - Características clínicas e demográficas dos pacientes em 2017.

\begin{tabular}{|c|c|c|c|c|}
\hline Características & $\begin{array}{l}\text { VSR negativo } \\
(\mathrm{n}=84)\end{array}$ & $\begin{array}{l}\text { VSR positivo } \\
(n=81)\end{array}$ & $\begin{array}{c}\text { Total } \\
(n=165)\end{array}$ & Valor $\boldsymbol{P}$ \\
\hline $\begin{array}{l}\text { Idade: } 0 \text { a } 24 \text { meses } \\
\text { Média } \pm D P(n)\end{array}$ & $7.0 \pm 5.0(n=84)$ & $5.8 \pm 5.0(n=81)$ & $6.4 \pm 5.1 \quad(n=165)$ & 0.083 \\
\hline $\begin{array}{l}\text { Sexo, } \mathbf{n}(\%) \\
\text { Feminino } \\
\text { Masculino }\end{array}$ & $\begin{array}{l}32(38.1) \\
52(61.9)\end{array}$ & $\begin{array}{l}34(42.0) \\
47(58.0)\end{array}$ & $\begin{array}{l}66(40.0) \\
99(60.0)\end{array}$ & 0.727 \\
\hline $\begin{array}{l}\text { Prematuridade, } \mathbf{n}(\%) \\
\text { Não } \\
\text { Sim }\end{array}$ & $\begin{array}{l}74(88.1) \\
10(11.9)\end{array}$ & $\begin{array}{l}72(88.9) \\
09(11.1)\end{array}$ & $\begin{array}{l}146(88.5) \\
19(11.5)\end{array}$ & 1.000 \\
\hline $\begin{array}{l}\text { Bronquiolite, n (\%) } \\
\text { Não } \\
\text { Sim }\end{array}$ & $\begin{array}{l}30(35.7) \\
54(64.3)\end{array}$ & $\begin{array}{l}11(13.6) \\
70(86.4)\end{array}$ & $\begin{array}{c}41(24.9) \\
124(75.1)\end{array}$ & 0.002 \\
\hline $\begin{array}{l}\text { Pneumonia, n (\%) } \\
\text { Não } \\
\text { Sim }\end{array}$ & $\begin{array}{l}76(90.5) \\
08(9.5)\end{array}$ & $\begin{array}{l}79(97.5) \\
02(2.5)\end{array}$ & $\begin{array}{c}155(94.0) \\
10(6.0)\end{array}$ & 0.099 \\
\hline $\begin{array}{l}\text { Uso antibiótico, n (\%) } \\
\text { Não } \\
\text { Sim }\end{array}$ & $\begin{array}{l}49(58.3) \\
35(41.7)\end{array}$ & $\begin{array}{l}53(65.4) \\
28(34.6)\end{array}$ & $\begin{array}{l}102(61.9) \\
63(38.1)\end{array}$ & 0.437 \\
\hline $\begin{array}{l}\text { Uso oseltamivir, } \mathbf{n}(\%) \\
\text { Não } \\
\text { Sim }\end{array}$ & $\begin{array}{l}54(64.3) \\
30(35.7)\end{array}$ & $\begin{array}{l}68(84.0) \\
13(16.0) \\
\end{array}$ & $\begin{array}{l}122(73.9) \\
43(26.1)\end{array}$ & 0.007 \\
\hline $\begin{array}{l}\text { Uso corticoide, } \mathbf{n}(\%) \\
\text { Não } \\
\text { Sim }\end{array}$ & $\begin{array}{l}43(51.2) \\
41(48.8)\end{array}$ & $\begin{array}{l}54(66.7) \\
27(33.3)\end{array}$ & $\begin{array}{l}97(58.8) \\
68(41.2)\end{array}$ & 0.063 \\
\hline $\begin{array}{l}\text { Inalação Hipertonica, n (\%) } \\
\text { Não } \\
\text { Sim }\end{array}$ & $\begin{array}{l}75(89.2) \\
09(10.8)\end{array}$ & $\begin{array}{l}61(75.3) \\
20(24.7)\end{array}$ & $\begin{array}{l}136(82.4) \\
29(17.6)\end{array}$ & 0.031 \\
\hline $\begin{array}{l}\text { Média (dias) enfermaria } \\
\text { Média } \pm P(n)\end{array}$ & $5.6 \pm 4.1(n=38)$ & $5.1 \pm 6.1(n=41)$ & $5.4 \pm 5.1(n=79)$ & 0.301 \\
\hline $\begin{array}{l}\text { Internação Unidade de terapia } \\
\text { intensiva, n (\%) } \\
\text { Não } \\
\text { Sim }\end{array}$ & $\begin{array}{l}72(85.7) \\
12(14.3)\end{array}$ & $\begin{array}{l}62(77.8) \\
19(22.2)\end{array}$ & $\begin{array}{l}134(81.9) \\
31(18.1)\end{array}$ & 0.191 \\
\hline $\begin{array}{l}\text { Média (dias) Unidade de } \\
\text { terapia intensiva } \\
\text { Média } D P(n)\end{array}$ & $9.3 \pm 5.4(n=12)$ & $9.3 \pm 5.1(n=19)$ & $9.3 \pm 5.2(n=31)$ & 0.949 \\
\hline $\begin{array}{l}\text { Oxitenda, n (\%) } \\
\text { Não } \\
\text { Sim }\end{array}$ & $\begin{array}{l}53(63.1) \\
31(36.9)\end{array}$ & $\begin{array}{l}35(43.2) \\
46(56.8)\end{array}$ & $\begin{array}{l}88(53.3) \\
77(46.7)\end{array}$ & 0.016 \\
\hline $\begin{array}{l}\text { Ventilação não invasiva, n(\%) } \\
\text { Não } \\
\text { Sim }\end{array}$ & $\begin{array}{l}76(91.6) \\
07(8.4)\end{array}$ & $\begin{array}{l}73(90.1) \\
08(9.9)\end{array}$ & $\begin{array}{c}149(90.3) \\
15(9.7)\end{array}$ & 0.960 \\
\hline $\begin{array}{l}\text { Ventilação Mecânica, n (\%) } \\
\text { Não } \\
\text { Sim }\end{array}$ & $\begin{array}{l}74(88.1) \\
10(11.9)\end{array}$ & $\begin{array}{l}65(80.2) \\
16(19.8)\end{array}$ & $\begin{array}{c}139(84.2) \\
26(15.8)\end{array}$ & 0.242 \\
\hline $\begin{array}{l}\text { Tempo (dias) Ventilação } \\
\text { mecânica } \\
\text { Média } D P(n)\end{array}$ & $8.3 \pm 3.2(n=10)$ & $9.3 \pm 5.1(n=16)$ & $8.8 \pm 4.2(n=26)$ & 0.873 \\
\hline
\end{tabular}

Fonte: Oliveira RF, et al., 2020.

A Tabela 3 mostra a gravidade das infecções pelo VSR, visto que aquelas com VSR positivo fizeram uso significativamente maior de ventilação mecânica. Além disso, apesar de não haver diferença significativa, permaneceram por tempo maior em UTI e em uso de ventilação mecânica. Na amostra total, o diagnóstico de bronquiolite também foi significativamente maior em pacientes com VSR positivo, conforme percebido em ambos os anos. O uso de oseltamivir apresentou significância, sendo maior em crianças com VSR negativo. 
Tabela 3 - Análise comparativa das características clínicas e demográficas dos pacientes, amostra total $(n=249)$.

\begin{tabular}{|c|c|c|c|c|}
\hline Características & $\begin{array}{c}\text { VSR negativo } \\
(n=84)\end{array}$ & $\begin{array}{c}\text { VSR positivo } \\
(n=81)\end{array}$ & Total $(n=165)$ & Valor $P$ \\
\hline $\begin{array}{l}\text { Ano, n (\%) } \\
2016 \\
2017\end{array}$ & $\begin{array}{l}48(36.4) \\
84(63.6)\end{array}$ & $\begin{array}{l}36(30.8) \\
81(69.2)\end{array}$ & $\begin{array}{c}84(33.7) \\
165(66.3)\end{array}$ & 0.425 \\
\hline $\begin{array}{l}\text { Idade: } 0 \text { a } 24 \text { meses } \\
\text { Média } \pm D P(n)\end{array}$ & $\begin{array}{c}6.7 \pm 5.1 \\
(132)\end{array}$ & $\begin{array}{c}5.6 \pm 5.1 \\
(117) \\
\end{array}$ & $\begin{array}{c}6.2 \pm 5.1 \\
(249)\end{array}$ & 0.101 \\
\hline $\begin{array}{l}\text { Sexo, n (\%) } \\
\text { Feminino } \\
\text { Masculino } \\
\end{array}$ & $\begin{array}{l}48(36.4) \\
84(63.6)\end{array}$ & $\begin{array}{l}50(42.7) \\
67(57.3) \\
\end{array}$ & $\begin{array}{c}98(39.3) \\
151(60.7)\end{array}$ & 0.370 \\
\hline $\begin{array}{l}\text { Prematuridade, } \mathbf{n}(\%) \\
\text { Não } \\
\text { Sim }\end{array}$ & $\begin{array}{l}117(88.6) \\
15(11.4) \\
\end{array}$ & $\begin{array}{c}100(85.5) \\
17(14.5) \\
\end{array}$ & $\begin{array}{l}217(87.1) \\
32(12.9)\end{array}$ & 0.579 \\
\hline $\begin{array}{l}\text { Bronquiolite, } \mathbf{n}(\%) \\
\text { Não } \\
\text { Sim }\end{array}$ & $\begin{array}{l}38(28.8) \\
94(71.2)\end{array}$ & $\begin{array}{c}16(13.7) \\
101(86.3)\end{array}$ & $\begin{array}{c}54(21.7) \\
195(78.3)\end{array}$ & 0.006 \\
\hline $\begin{array}{l}\text { Insuficiência Respiratória } \\
\text { Aguda, n (\%) } \\
\text { Não } \\
\text { Sim }\end{array}$ & $\begin{array}{l}99(75.0) \\
33(25.0) \\
\end{array}$ & $\begin{array}{l}98(83.8) \\
19(16.2) \\
\end{array}$ & $\begin{array}{l}197(79.1) \\
52(20.9) \\
\end{array}$ & 0.123 \\
\hline $\begin{array}{l}\text { Pneumonia, n (\%) } \\
\text { Não } \\
\text { Sim }\end{array}$ & $\begin{array}{l}114(86.4) \\
18(13.6)\end{array}$ & $\begin{array}{c}106(90.6) \\
11(9.4) \\
\end{array}$ & $\begin{array}{l}220(88.3) \\
29(11.7)\end{array}$ & 0.400 \\
\hline $\begin{array}{l}\text { Internação enfermaria (dias) } \\
\text { Média DP }(n)\end{array}$ & $5.2 \pm 3.8(55)$ & $4.8 \pm 5.6(59)$ & $5.0 \pm 4.7(114)$ & 0.089 \\
\hline $\begin{array}{l}\text { Internação UTI (dias) } \\
\text { Média土DP }(\mathrm{n})\end{array}$ & $9.2 \pm 5.2(15)$ & $10.2 \pm 7.7(31)$ & $9.7 \pm 6.4(46)$ & 0.856 \\
\hline $\begin{array}{l}\text { Uso antibiótico, n (\%) } \\
\text { Não } \\
\text { Sim }\end{array}$ & $\begin{array}{l}87(65.9) \\
45(34.1)\end{array}$ & $\begin{array}{l}76(65.0) \\
41(35.0)\end{array}$ & $\begin{array}{c}163(65.4) \\
86(34.6)\end{array}$ & 0.981 \\
\hline $\begin{array}{l}\text { Uso oseltamivir, } \mathbf{n}(\%) \\
\text { Não } \\
\text { Sim }\end{array}$ & $\begin{array}{l}81(61.4) \\
51(38.6) \\
\end{array}$ & $\begin{array}{l}98(83.8) \\
19(16.2) \\
\end{array}$ & $\begin{array}{l}179(71.9) \\
70(28.1) \\
\end{array}$ & $<0.001$ \\
\hline $\begin{array}{l}\text { Uso corticoide, } \mathbf{n}(\%) \\
\text { Não } \\
\text { Sim }\end{array}$ & $\begin{array}{l}66(50.0) \\
66(50.0) \\
\end{array}$ & $\begin{array}{l}71(60.7) \\
46(39.3) \\
\end{array}$ & $\begin{array}{l}137(55.0) \\
112(45.0) \\
\end{array}$ & 0.118 \\
\hline $\begin{array}{l}\text { Inalação Hipertônica, n (\%) } \\
\text { Não } \\
\text { Sim }\end{array}$ & $\begin{array}{c}109(82.6) \\
23(17.4) \\
\end{array}$ & $\begin{array}{l}88(75.2) \\
29(24.8) \\
\end{array}$ & $\begin{array}{c}197(79.1) \\
52(20.9) \\
\end{array}$ & 0.204 \\
\hline $\begin{array}{l}\text { Oxitenda, n (\%) } \\
\text { Não } \\
\text { Sim }\end{array}$ & $\begin{array}{l}65(49.2) \\
67(50.8) \\
\end{array}$ & $\begin{array}{l}42(35.9) \\
75(64.1) \\
\end{array}$ & $\begin{array}{l}107(43.0) \\
142(57.0)\end{array}$ & 0.046 \\
\hline $\begin{array}{l}\text { Ventilação não invasiva, n (\%) } \\
\text { Não } \\
\text { Sim }\end{array}$ & $\begin{array}{c}120(90.8) \\
12(9.2) \\
\end{array}$ & $\begin{array}{c}105(89.7) \\
12(10.3)\end{array}$ & $\begin{array}{c}225(90.3) \\
24(9.7)\end{array}$ & 0.939 \\
\hline $\begin{array}{l}\text { Ventilação mecânica, n (\%) } \\
\text { Não } \\
\text { Sim }\end{array}$ & $\begin{array}{c}118(89.4) \\
14(10.6)\end{array}$ & $\begin{array}{l}94(80.3) \\
23(19.7)\end{array}$ & $\begin{array}{c}212(85.1) \\
37(14.9)\end{array}$ & 0.068 \\
\hline 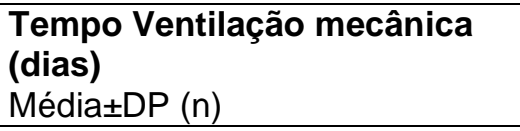 & $9.1 \pm 5.5(14)$ & $10.5 \pm 5.9(23)$ & $9.8 \pm 5.7(37)$ & 0.392 \\
\hline
\end{tabular}

Fonte: Oliveira RF, et al., 2020.

Conforme dados demonstrados na Tabela 4, comparando-se as variáveis entre os anos, nas crianças com VSR positivo em 2017 houve menor número de diagnósticos de pneumonia e insuficiência respiratória aguda, entretanto houve maior número de crianças precisando de oxigenoterapia, sendo significativamente maior o 
uso de oxitenda e de cateter de oxigênio tipo óculos. O uso de ventilação mecânica não apresentou significância, mas em 2017 seu uso também foi maior entre as crianças com VSR positivo. As demais características não apresentaram diferença significativa entre os grupos.

Tabela 4 - Análise comparativa das características clínicas e demográficas dos pacientes entre os anos.

\begin{tabular}{|c|c|c|c|c|}
\hline Características & $\begin{array}{c}\text { Ano } 2016 \\
(n=84)\end{array}$ & $\begin{array}{l}\text { Ano } 2017 \\
(n=165)\end{array}$ & $\begin{array}{c}\text { Total } \\
(n=249)\end{array}$ & Valor $P$ \\
\hline $\begin{array}{l}\text { Idade: } 0 \text { a } 24 \text { meses } \\
\text { Média } \pm D P(n)\end{array}$ & $6.1 \pm 5.2(84)$ & $6.4 \pm 5.1(165)$ & $6.2 \pm 5.1(249)$ & 0.422 \\
\hline $\begin{array}{l}\text { Prematuridade, } \mathbf{n}(\%) \\
\text { Não } \\
\text { Sim }\end{array}$ & $\begin{array}{l}71(84.5) \\
13(15.5)\end{array}$ & $\begin{array}{c}146(88.5) \\
19(11.5)\end{array}$ & $\begin{array}{c}217(87.1) \\
32(12.9)\end{array}$ & 0.495 \\
\hline $\begin{array}{l}\text { Bronquiolite, n (\%) } \\
\text { Não } \\
\text { Sim }\end{array}$ & $\begin{array}{l}13(15.5) \\
71(84.5) \\
\end{array}$ & $\begin{array}{c}41(24.9) \\
124(75.1) \\
\end{array}$ & $\begin{array}{r}54(21.7) \\
195(78.3) \\
\end{array}$ & 0.125 \\
\hline $\begin{array}{l}\text { Insuficiência respiratória } \\
\text { aguda, } \mathbf{n}(\%) \\
\text { Não } \\
\text { Sim } \\
\end{array}$ & $\begin{array}{l}55(65.5) \\
29(34.5)\end{array}$ & $\begin{array}{l}142(86.0) \\
23(14.0) \\
\end{array}$ & $\begin{array}{l}197(79.1) \\
52(20.9)\end{array}$ & $<0.001$ \\
\hline $\begin{array}{l}\text { Pneumonia, n (\%) } \\
\text { Não } \\
\text { Sim }\end{array}$ & $\begin{array}{l}65(77.4) \\
19(22.6) \\
\end{array}$ & $\begin{array}{c}155(93.9) \\
10(6.1) \\
\end{array}$ & $\begin{array}{l}220(88.3) \\
29(11.7)\end{array}$ & $<0.001$ \\
\hline $\begin{array}{l}\text { Internação enfermaria (dias) } \\
\text { Média DP }(\mathrm{n})\end{array}$ & $4.2 \pm 4.5(35)$ & $5.4 \pm 5.2(79)$ & $4.8 \pm 4.8(114)$ & 0.038 \\
\hline $\begin{array}{l}\text { Internação UTI (dias) } \\
\text { Média_DP (n) }\end{array}$ & $11.0 \pm 9.7(15)$ & $9.3 \pm 5.1(31)$ & $10.1 \pm 7.4(46)$ & 0.866 \\
\hline $\begin{array}{l}\text { Uso antibiótico, n (\%) } \\
\text { Não } \\
\text { Sim }\end{array}$ & $\begin{array}{l}61(71.8) \\
23(28.2)\end{array}$ & $\begin{array}{c}102(62.0) \\
63(38.0)\end{array}$ & $\begin{array}{c}163(65.4) \\
86(34.6)\end{array}$ & 0.162 \\
\hline $\begin{array}{l}\text { Uso oseltamivir, n (\%) } \\
\text { Não } \\
\text { Sim }\end{array}$ & $\begin{array}{l}57(61.1) \\
27(32.9)\end{array}$ & $\begin{array}{c}122(74.2) \\
43(25.8)\end{array}$ & $\begin{array}{c}179(71.9) \\
70(28.1)\end{array}$ & 0.297 \\
\hline $\begin{array}{l}\text { Corticoide, n (\%) } \\
\text { Não } \\
\text { Sim }\end{array}$ & $\begin{array}{l}40(47.6) \\
44(52.4)\end{array}$ & $\begin{array}{l}97(58.8) \\
68(41.2)\end{array}$ & $\begin{array}{l}137(55.0) \\
112(45.0)\end{array}$ & 0.123 \\
\hline $\begin{array}{l}\text { Inalação Hipertônica, n (\%) } \\
\text { Não } \\
\text { Sim }\end{array}$ & $\begin{array}{l}61(72.6) \\
23(27.4)\end{array}$ & $\begin{array}{c}136(82.4) \\
29(17.6)\end{array}$ & $\begin{array}{c}197(79.1) \\
52(20.9)\end{array}$ & 0.102 \\
\hline $\begin{array}{l}\text { Cateter tipo óculos, } \mathbf{n}(\%) \\
\text { Não } \\
\text { Sim }\end{array}$ & $\begin{array}{l}22(26.2) \\
62(73.8)\end{array}$ & $\begin{array}{l}78(47.3) \\
87(52.7)\end{array}$ & $\begin{array}{l}100(40.1) \\
149(59.9)\end{array}$ & 0.002 \\
\hline $\begin{array}{l}\text { Oxitenda, n (\%) } \\
\text { Não } \\
\text { Sim }\end{array}$ & $\begin{array}{l}19(22.6) \\
65(77.4)\end{array}$ & $\begin{array}{l}88(53.3) \\
77(46.7)\end{array}$ & $\begin{array}{l}107(43.0) \\
142(57.0)\end{array}$ & $<0.001$ \\
\hline $\begin{array}{l}\text { Ventilação não invasiva, n (\%) } \\
\text { Não } \\
\text { Sim }\end{array}$ & $\begin{array}{l}75(89.3) \\
09(10.7) \\
\end{array}$ & $\begin{aligned} & 150(90.9) \\
& 15(9.1) \\
&\end{aligned}$ & $\begin{aligned} & 225(90.3) \\
& 24(9.7) \\
&\end{aligned}$ & 0.866 \\
\hline $\begin{array}{l}\text { Ventilação mecânica, n (\%) } \\
\text { Não } \\
\text { Sim }\end{array}$ & $\begin{array}{l}73(87.0) \\
11(13.0)\end{array}$ & $\begin{array}{c}139(84.2) \\
26(15.8)\end{array}$ & $\begin{array}{c}212(85.1) \\
37(14.9)\end{array}$ & 0.711 \\
\hline $\begin{array}{l}\text { Tempo Ventilação mecânica } \\
\text { (dias) } \\
\text { Média } \pm \text { DP }(n)\end{array}$ & $9.3 \pm 5.6(11)$ & $10.2 \pm 5.8(26)$ & $9.8 \pm 5.7(36)$ & 0.525 \\
\hline
\end{tabular}

Fonte: Oliveira RF, et al., 2020.

\section{DISCUSSÃO}

O número de casos de crianças submetidas ao teste rápido para VSR aumentou de 2016 para 2017. Como consequência, a taxa de crianças infectadas por esse vírus também se elevou. Esse aumento se justifica devido à rotina de realização do teste ter sido iniciada em 2016, e consequentemente, após as equipes 
assistenciais estarem habituadas, as coletas aumentaram. Isso também pode ter se dado devido ao aumento do número de pacientes de 2016 para 2017, que procuraram o Pronto Socorro Infantil durante o período de sazonalidade, pois a infecção pelo vírus está relacionada à alta transmissibilidade, além da sazonalidade, associada às baixas temperaturas que consequentemente, aumentam o contato entre as pessoas em ambientes fechados (FERONE EA, et al., 2013; FREITAS ARR, 2014; BRASIL, 2011; CRUZ DM, et al., 2016; PARIS F, 2012).

Neste estudo, assim como na literatura, a bronquiolite foi a apresentação mais frequente das infecções do trato respiratório inferior em ambos os anos, principalmente nas crianças infectadas pelo VSR. Este resultado corrobora com estudos que apontam a relação entre internações por bronquiolite devido ao VSR e a circulação viral (FERGIE J e PURCELL K, 2014; COUTINHO SE, et al., 2015; PIÑEROS JG, et al., 2013; SOUZA APDS, et.al., 2016).

A média de idade aumentou de 2016 para 2017, embora não haja diferença significativa ao comparar-se os grupos, nos dois anos, nem na amostra total. Esse resultado se difere de outras pesquisas em que a idade cronológica foi destacada como fator de risco para a infecção pelo VSR, todavia se assemelha quando observado um predomínio no sexo masculino (MAÇÃO P, et al., 2011; NAVES KC, 2018; BRASIL, 2017).

Em ambos os anos, o uso de antiviral, oseltamivir, foi empregado com maior frequência em crianças, nas quais foi descartada a infecção pelo VSR. O protocolo atual indica o uso de oseltamivir em infecções por influenza, podendo justificar seu uso em situações nas quais foi descartada a infecção pelo VSR. É possível que o processo inflamatório causado pela infecção pelo VSR e a semelhança com a apresentação clínica da infecção pelo vírus influenza condicionem o uso do antiviral em crianças com VSR positivo também. Essa dificuldade também se dá devido à limitação de nosso serviço, que não conta com o painel viral. Neste estudo, a taxa de crianças que utilizou essa terapêutica com VSR positivo foi reduzida. Em 2017, o uso foi em apenas treze crianças (16\%) e em 2016 em seis crianças (16.7\%) (NAVES KC, 2018; BRASIL, 2017).

Em protocolo pediátrico brasileiro, o uso da solução salina hipertônica pode ser considerado, entretanto, os resultados são observados quando esta é utilizada por no mínimo 3 dias (MOURA AA, et al., 2017). Nossa amostra demonstrou que o uso da solução salina hipertônica foi por tempo menor (média de 2.4 dias) que o indicado pelo protocolo. No entanto, o uso em crianças com VSR positivo foi usualmente maior $(n=20 ; 24.7 \%)$ quando comparado ao grupo de crianças com VSR negativo $(n=9 ; 10.8 \%)$.

As crianças apresentam taxa metabólica alta e, portanto, consomem mais oxigênio do que os adultos. Entretanto, possuem menor capacidade pulmonar residual funcional e menores reservas de oxigênio. Em função disso, em diversos estudos a oxigenoterapia é descrita como medida de suporte muito utilizada em casos de infecção do trato respiratório (SOUZA APDS, et al., 2016; ELIA CD, et al., 2005; BEDRAN RM, et al., 2016).

Dentre as possibilidades de oxigenoterapia neste estudo, a oxitenda em 2017, foi utilizada em algum momento da internação, em grande parte dos pacientes, independente do resultado de VSR. Em nossos resultados, em 2017, o uso de oxitenda ocorreu em $56.8 \%$ dos pacientes com VSR positivo e $36.9 \%$ dos pacientes com VSR negativo. Em 2016 , em $80.6 \%$ dos pacientes com VSR positivo e $75 \%$ nos pacientes com VSR negativo. Esse resultado era esperado, pois a escolha da forma de administração do oxigênio depende, principalmente, da eficiência do sistema a ser empregado. Em crianças menores de dois anos de idade, a oxitenda se adapta melhor, ofertando mais conforto e assegurando os benefícios clínicos em sua evolução (MATSUNO AK, 2012).

O estudo revelou que houve aumento da incidência do VSR de $2016(42,9 \%)$, para 2017 (49,1\%), chegando a quase metade da amostra. Apesar do aumento significativo do número de casos de insuficiência respiratória aguda de 2016 para 2017, em 2017 todos os pacientes apresentaram resultado negativo para o vírus H1N1 ( $n=53 ; 100 \%)$. Já em 2016, mesmo havendo menor frequência de coleta de investigação para o vírus H1N1 $(n=12), 16.6 \%$ apresentaram vírus H1N1 positivo $(n=2)$.

As variáveis que apresentaram diferença significativa entre os grupos quanto ao resultado do VSR, entre os anos de 2017 e 2016, sugerem que em 2016 os casos das crianças infectadas pelo VSR apresentaram 
maior gravidade clínica quando comparados aos casos de crianças com VSR negativo naquele mesmo ano, tendo como desfecho maior frequência de internação na UTI pediátrica e evolução para a ventilação mecânica. Em estudo recente, que incluiu 176 lactentes com diagnóstico de bronquiolite e/ou pneumonia, foram identificados 120 lactentes com infecção única por VSR e 55 com coinfecção por outros vírus. A conclusão do estudo foi que o desfecho de gravidade avaliado foi semelhante entre o grupo com infecção única devido ao VSR e o grupo com coinfecção. Portanto, a coinfecção viral não parece alterar o prognóstico de lactentes hospitalizados com infecção por VSR, o que comprova a patogenicidade desse vírus (DE PAULIS M, et al., 2011).

As infecções pelo VSR geralmente apresentam boa evolução, mas em sua forma mais grave podem apresentar necessidade de internação em UTI pediátrica e ventilação mecânica. A literatura descreve diversos fatores que podem estar relacionados às formas mais graves como a baixa idade, gênero masculino, prematuridade, cardiopatias, entre outros (ALVAREZ AE, et al., 2013; MAÇÃO P, et al., 2011). Entre as comorbidades, neste estudo foi avaliada a prematuridade, e posteriormente, comparados os dados entre os anos. Apesar de não haver diferença estatisticamente significativa, em 2017 a taxa de crianças com VSR positivo prematuras $(n=9 ; 11.1 \%)$ foi menor que em $2016(n=8 ; 22.2 \%)$.

Além disso, a maioria dos casos de infecção pelo VSR ocorre durante o primeiro ano de vida e alcança um pico de incidência entre os dois e seis meses de idade, sendo potencialmente graves nessa idade (MAÇÃO P, et al., 2011). As crianças com VSR positivo em 2016 apresentaram média de idade (5.7 meses) menor em comparação ao ano de 2017 (5.8 meses). Portanto, neste estudo, apesar de não haver diferenças significativas para idade e prematuridade entre os anos, estas podem estar potencialmente relacionadas à maior gravidade dos quadros clínicos em 2016.

\section{CONCLUSÃO}

Entre os anos de 2016 e 2017, houve aumento no número de casos de crianças com desconforto respiratório e incidência de VSR. Houve diminuição da incidência do vírus H1N1, mesmo havendo aumento da frequência de investigação do vírus entre os anos. Então, no serviço estudado, o VSR foi muito incidente, sendo o agente viral mais identificado nas infecções do trato respiratório inferior, contribuindo para o alto número de hospitalizações, principalmente, no período de sazonalidade. Além disso, o estudo concluiu que em 2016, o quadro clínico de crianças infectadas pelo VSR foi significativamente mais grave em comparação a 2017, estando potencialmente relacionados às maiores incidências dos fatores de risco para gravidade clínica em quadros respiratórios infantis, como a baixa idade e a prematuridade.

\section{REFERÊNCIAS}

1. ALVAREZ AE, et al. Epidemiological and genetic characteristics associa 7 ted with the severity of acute viral bronchiolitis by respiratory syncytial virus. J Pediatr (Rio J), 2013; 89: 531-43.

2. BEDRAN RM, et al. Atualizações no tratamento de bronquiolite viral aguda. Ver Med Minas Gerais, 2016; 26(Supl 2): S23-S25.

3. BENITES ECA, et al. Acute respiratory viral infections in pediatric cancer patients undergoing chemotherapy. J Pediatr (Rio J)., 2014; 90: 370-6.

4. BRASIL. Ministério da Saúde. Secretaria de Atenção à Saúde- Departamento de Atenção Básica. Atenção ao prénatal de baixo risco. Brasília: Ministério da Saúde; 2013. Disponível em: http://bvsms.saude.gov.br/bvs/publicacoes/atencao_pre_natal_baixo_risco.pdf. Acessado em: 18 de Abril de 2020.

5. BRASIL. Ministério da saúde. Secretária de Ciência, tečnologia e insumos estratégicos- Departamento de Gestão e Incorporação de Tecnologia em Saúde. Palivizumabe para prevenção da infecção pelo vírus sincicial respiratório. 2012. Disponível em: http://conitec.gov.br/images/Incorporados/Palivizumabe-VirusSincicial-final.pdf. Acessado em: 28 de Maio de 2020.

6. BRASIL. Ministério da Saúde. Secretária de Vigilância em Saúde- Departamento de Vigilância das doenças transmissíveis. Protocolo de tratamento de influenza 2017. Brasília: Ministério da Saúde; 2017. Disponível em: http://portalarquivos2.saude.gov.br/images/pdf/2018/abril/19/protocolo-influenza-2017.pdf. Acessado em: 28 de Maio de 2020.

7. COUTINHO SE, et al. Os múltiplos agentes associados à bronquiolite aguda e à gravidade da doença. Bol Client Pediatr., 2015; 04(1): 5-9.

8. CRUZ DM, et al. Internações hospitalares, óbitos, custos com doenças respiratórias e sua relação com alterações climáticas no município de São Carlos- SP, Brasil. Medicina (Ribeirão Preto), 2016; 49(3):248-57. 
9. DE PAULIS M, et al. Severity of viral coinfection in hospitalized infants with respiratory syncytial virus infection. J Pediatr (Rio J), 2011; 87(4): 307-13.

10. ELIA CD, et al. Infecções do trato respiratório em crianças hospitalizadas menores de um ano de idade. Revista Sociedade Brasileira de Medicina Tropical, 2005; 38(1): 7-10.

11. FERGIE J, PURCELL K. Respiratory Syncytial Virus Laboratory Surveillance and Hospitalization Trends in South Texas. The Pediatric Infectious Disease Journal, 2014; 26(11 Suppl): S51-4.

12. FERLINI R, et al. Características e evolução de crianças com bronquiolite viral aguda submetidas à ventilação mecânica. Rev Bras Ter Intensiva, 2016; 28(1): 55-61.

13. FERONE EA, et al. Clinical and epidemiological aspects related to the detection of adenovirus or respiratory syncytial virus in infants hospitalized for acute lower respiratory tract infection. J Pediatr (Rio J), 2014; 90: 42.

14. FONSECA S, et al. Pneumonias pneumocócicas e pneumonias por influenza A: Estudo comparativo. Revista da sociedade portuguesa de medicina interna, 2017; $24: 2$.

15. FRAUCHES DO, et al. Doenças respiratórias em crianças e adolescentes: um perfil dos atendimentos na atenção primária em Vitória/ES. Rev Bras Med Fam Comunidade, 2017; 12(39): 1-11.

16. FREITAS ARR. Impactos dos vírus Influenza e Sincicial Respiratório na Mortalidade e Internações e suas Implicação para as políticas Públicas no Brasil. Dissertação (pós-graduação). Campinas (SP): Unicamp; 2014.

17. MAÇÃO P, et al. Bronquiolite aguda: Estudo prospectivo. Acta Med Port, 2011; 24(S2): 407-412.

18. MAGALHAES EF, et al. Análise da prevalência de vírus respiratórios em crianças atendidas em um hospital universitário do sul de Minas Gerais. Rev Med de Minas Gerais, 2017; 27: e27-1870.

19. MATSUNO AK. Insuficiência respiratória aguda na criança. Medicina (Ribeirão Preto), 2012; 45(2): $168-84$.

20. MESQUITA FS, et al. Rapid antigen detection test for respiratory syncytial virus diagnosis as a diagnostic tool. J Pediatr (Rio J), 2017; 93: 246-52.

21. MONTEIRO AIMP, et al. Infecções respiratórias em crianças menores de dois anos de idade submetidas a profilaxia com palivizumabe. Rev Paul Pediatr., 2014; 32(2): 152-8.

22. MOURA AA, et al. Sociedade Brasileira de Pediatria. Diretrizes para o manejo da infecção causada pelo vírus sincicial respiratório (VSR)-2017. Brasil- Sociedade Brasileira de Pediatria. Departamentos científicos de cardiologia, imunização, infectologia, neonatologia e pneumologia; 2017.

23. NAVES KC. Análise crítica do tratamento instituído a crianças com infecção por vírus sincicial respiratório em um hospital público Dissertação (mestrado). São Paulo (SP): USP; 2018.

24. PARIS F. Epidemiologia dos vírus respiratórios e avaliação das características genéticas do vírus sincicial respiratório entre crianças atendidas no Hospital de Clínicas de Porto Alegre [página inicial na internet]. Universidade Federal do $\begin{array}{lllll}\text { Rio Grande } & \text { do } & 2012 . & \text { Acessado }\end{array}$ https://lume.ufrgs.br/bitstream/handle/10183/70397/000877212.pdf?sequence=1\&isAllowed=y

25. PINEROS JG, et al. Respiratory syncytial virus infection as a cause of hospitalization in population under 1 year in Colombia. J Pediatr (Rio J), 2013; 89: 544-8.

26. SOUZA APD, et al. Falta de associação entre carga viral e gravidade da bronquiolite aguda em lactentes. J Bras Pneumol., 2016; 42(4): 261-265.

27. SOUZA PG, et al. Infecções respiratória aguda baixa em crianças indígenas guarani, Brasil. Rev Paul Pediatr., 2018; 36(2): 123-131. 